\title{
Synthesis and comparison of the activities of a catalyst supported on two silicate materials
}

\author{
Eduardo G. Vieira ${ }^{\text {a, }}{ }^{*}$, Rafael O. Silva ${ }^{a}$, Devaney R. do Carmo ${ }^{\text {a }}$, Enes F. Junior ${ }^{\mathrm{c}}$, \\ Newton L. Dias Filho ${ }^{\text {a, b, ** }}$ \\ ${ }^{a}$ Departamento de Física e Química, Unesp-Univ Estadual Paulista, Av. Brasil, 56-Centro, Caixa Postal 31, CEP 15385-000, Ilha Solteira, São Paulo, Brazil \\ ${ }^{\mathrm{b}}$ Universidade do Extremo Sul Catarinense, Av. Universitaria, 1105, CP 3167, CEP 88806-000, Criciúma, SC, Brazil

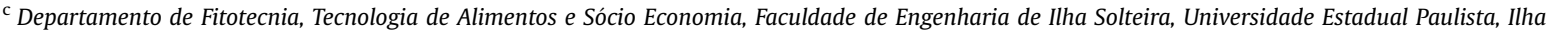 \\ Solteira, São Paulo, Brazil
}

\section{H I G H L I G H T S}

- Immobilization of $\left[\mathrm{W}(\mathrm{CO})_{3} \mathrm{I}_{2}\left(\mathrm{NCCH}_{3}\right)_{2}\right]$ complex onto mesoporous supports.

- Synthesis and characterization of new mesoporous catalysts.

- The new catalysts exhibit great catalytic activity in the epoxidation of 1-octene.

- Recyclable catalysts with excellent reusability and stability.

\section{A R T I C L E I N F O}

\section{Article history:}

Received 15 April 2016

Received in revised form

8 November 2016

Accepted 14 January 2017

Available online 25 January 2017

\section{Keywords:}

Heterogeneous catalysts

Organometallic complex

Catalysts

1-Octene

\begin{abstract}
A B S T R A C T
The focus of this work is inspecting the synthesis and comparison of the activities of a catalyst supported on two silicate materials in the epoxidation of 1-octene. The two new catalyst materials were characterized by infrared spectroscopy, elemental analysis, solid-state ${ }^{29} \mathrm{Si}$ and ${ }^{13} \mathrm{C}$ nuclear magnetic resonance, scanning electronic microscope (SEM) and analysis of nitrogen. Lastly, the two new catalysts, SilsesqTCA- $\left[\left(\mathrm{W}(\mathrm{CO})_{3} \mathrm{I}_{2}\right)_{3}\right]$ and Silica-TCA- $\left[\mathrm{W}(\mathrm{CO})_{3} \mathrm{I}_{2}\right]$ were tested as catalysts in reactions of epoxidation of 1octene and compared with their analogue not supported [W(CO $)_{3} \mathrm{I}_{2}$ (thiocarbamide)]. After an extensive literature search, we verified that our work is the first that has reported the immobilization process of $\left[\mathrm{W}(\mathrm{CO})_{3} \mathrm{I}_{2}\left(\mathrm{NCCH}_{3}\right)_{2}\right]$ on silsesquioxane and silica gel functionalized with propyl-thiocarbamide groups and their applications as catalysts of reactions of catalytic epoxidation of 1-octene.
\end{abstract}

(c) 2017 Elsevier B.V. All rights reserved.

\section{Introduction}

For the last few years, the demand for active heterogeneous catalysts and easy recycling has been desired by many industrial processes for many different applications. Among the various processes, the oxidation of olefins has been industrially important, because the epoxides obtained are used as intermediates in polymer synthesis reactions, production of pharmaceuticals and fine

\footnotetext{
* Corresponding author.

** Corresponding author. Departamento de Física e Química, Unesp-Univ Estadual Paulista, Av. Brasil, 56-Centro, Caixa Postal 31, CEP 15385-000, Ilha Solteira, São Paulo, Brazil.

E-mail addresses: eduardogv5007@gmail.com (E.G. Vieira), nldias@unesc.net (N.L. Dias Filho).
}

chemicals [1]. Homogeneous catalysts are more efficient in most industrial processes and in olefin epoxidation it is no different, however, it shows significant drawbacks, such as leaching, difficulty in separation and reuse that leads to their loss [2]. Moreover, supported catalysts have some advantages such as high applicability, high sensitivity to poisoning, high possibility of modification, excellent thermal stability, long life, easy separation and recovery of the catalyst $[3,4]$. Recently, organometallic complexes have received special attention, because the advancement of synthetic routes have contributed to the grafting of organometallic complexes in the structure of several materials. Organometallic complexes can coordinate easily in various types of supports, resulting in robust and efficient catalysts in many industrial catalytic processes. The homogeneous catalysts based on organometallic complexes can be used as heterogeneous catalysts from the 
immobilization on a solid support. In the field of catalysis, recent studies have used various supports in the search for catalysts with high selectivity and efficient in the epoxidation of olefins, i.e. carbon nanotubes [5] organic polymers [6] and amorphous aluminum phosphate [7]. Silicon-based compounds are promising supports for grafting of organometallic complexes, due to the possibility of surface modification by a variety of organic compounds [8,9]. Thus, polyhedral oligomeric silsesquioxane are considered an important class of solid supports. Silsesquioxanes have a rigid inorganic core of Si-O-Si with nanometric size of 1,5-3 nm, high asymmetry, high thermal stability, as well as radicals that can be covalently linked to organic substituents aryl, vinyl, allyl, and aromatic ring substituted $[10,11]$. Thus, polyhedral oligomeric silsesquioxane and silica gel chemically modified have high surface areas and groups that can be easily modified by various organic functional groups by nucleophilic substitution [12-14].

The aim of this study was to explore the use of mesoporous supports based on silsesquioxane and silica gel modified with thiocarbamide as well as the reaction of these mesoporous materials with the complex $\left[\mathrm{W}(\mathrm{CO})_{3} \mathrm{I}_{2}\left(\mathrm{NCCH}_{3}\right)_{2}\right]$ to optimize the synthesis of the two new catalysts. The two new Silsesq-TCA- $\left[\left(\mathrm{W}(\mathrm{CO})_{3} \mathrm{I}_{2}\right)_{3}\right]$ and Silica-TCA- $\left[\mathrm{W}(\mathrm{CO})_{3} \mathrm{I}_{2}\right]$ catalysts were tested in olefin epoxidation reactions and compared with the homogeneous catalyst $\left[\mathrm{W}(\mathrm{CO})_{3} \mathrm{I}_{2}\right.$ (thiocarbamide)].

\section{Investigational procedures}

\subsection{Additional information}

The chemicals were purchased from Sigma-Aldrich.

All solvents used in this study were previously purified, unless otherwise indicated.

The complex $\left[\mathrm{W}(\mathrm{CO})_{2} \mathrm{X}\left(\mathrm{NCCH}_{3}\right)_{2}\right](\mathrm{X}=\mathrm{I}, \mathrm{X}=\mathrm{Cl}$ or $\mathrm{X}=\mathrm{Br})$ was prepared according to literature methods, but with modifications $[15,16]$.

The infrared analyzes were obtained using a Nicolet 5DXB Instruments spectrometer.

The analysis of nuclear magnetic resonance of carbon and silicon were performed on a Bruker Avance 400 spectrometer in the chemical institute of Araraquara/SP.

The electronic scanning microscopy images were taken in an EVO LS15 - Carl Zeiss and coated with gold.

A Mass spectrometry with inductively coupled plasma (ICP-MSSeries X 2 - Thermo Scientific) was used in this paper.

\subsection{Preparatives}

\subsubsection{Synthesis of organometallic complex $\left[\mathrm{W}(\mathrm{CO})_{3} \mathrm{I}_{2}\left(\mathrm{NCCH}_{3}\right)_{2}\right]$}

The complex $\left[\mathrm{W}(\mathrm{CO})_{3} \mathrm{I}_{2}\left(\mathrm{NCCH}_{3}\right)_{2}\right]$ was prepared according to literature $[15,16]$ with modifications.

In a flask containing dry acetonitrile $(160 \mathrm{~mL})$ was added about $6.54 \mathrm{~g}(18.6 \mathrm{mmol})$ of $\left[\mathrm{W}(\mathrm{CO})_{6}\right]$ under reflux and nitrogen atmosphere for $96 \mathrm{~h}$. The resulting solution was refrigerated to $-20^{\circ} \mathrm{C}$, and about $4.72 \mathrm{~g}$ (18.6 mmol) of iodine was added. A brown-red solution was formed immediately after the addition of iodine. Finally, the solvent was removed in vacuo yielding a dark brown complex (yield $5.90 \mathrm{~g}, 90,21 \%$ ).

\subsubsection{Synthesis of homogeneous catalyst - $\left[\mathrm{W}(\mathrm{CO})_{3} \mathrm{I}_{2}(\mathrm{TCA})\right]$}

A solution of $\left[\mathrm{W}(\mathrm{CO})_{3} \mathrm{I}_{2}\left(\mathrm{NCCH}_{3}\right)_{2}\right](1.00 \mathrm{mmol})$ in $\mathrm{CH}_{2} \mathrm{Cl}_{2}(10 \mathrm{~mL})$ was added in a solution of the thiocarbamide ligand (TCA) (1.00 mmol) in $\mathrm{CH}_{2} \mathrm{Cl}_{2}(10 \mathrm{~mL})$. The reaction was maintained at $298 \mathrm{~K}$ and shaken for $6 \mathrm{~h}$, then the solvent was evaporated giving a yellow solid which was purified by washing with hexane and dried in vacuo (96\% yield).

\subsubsection{Synthesis of heterogeneous catalyst - Silsesq-TCA- $\left[\left(\mathrm{W}(\mathrm{CO})_{3} I_{2}\right)_{3}\right]$}

The Silsesq-TCA- $\left[\left(\mathrm{W}(\mathrm{CO})_{3} \mathrm{I}_{2}\right)_{3}\right]$ was prepared based on the study of the $\left[\mathrm{W}(\mathrm{CO})_{3} \mathrm{I}_{2}\left(\mathrm{NCCH}_{3}\right)_{2}\right]$ immobilization on Silsesq-TCA, using the following procedure:

In a flask containing $4 \mathrm{~L}$ of $\mathrm{CH}_{3} \mathrm{OH}$ was added $225 \mathrm{~mL}$ of 3chloropropyltriethoxysilane (CPTES) and $135 \mathrm{~mL}$ of $\mathrm{HCl}$ under nitrogen atmosphere. The solution was vigorously stirred and after 6 weeks the white solid formed was filtered, washed and dried. The resulting material, named Octakis(3-chloropropyl)octasilsesquioxane (Silsesq-PrCl) gave a yield of $39 \%$.

About $5.82 \mathrm{~g}$ of thiocarbamide was added during a period of $60 \mathrm{~min}$ to a suspension of $1.83 \mathrm{~g}$ of $\mathrm{NaH}$ in $100 \mathrm{~mL}$ of DMF under nitrogen. The reaction system was shaken at a temperature of $0{ }^{\circ} \mathrm{C}$ for three hours. Next, $10 \mathrm{~g}$ of Silsesq-PrCl in DMF was added to the reaction system and the temperature was raised to $80^{\circ} \mathrm{C}$ for $24 \mathrm{~h}$ forming a yellow solution. To precipitate the nanomaterial, ethanol was added to reaction; the precipitated material was filtered to give the modified silsesquioxane Silsesq-TCA in 70\% yield.

The Silsesq-TCA-[W(CO $\left.)_{3} \mathrm{I}_{2}\right]$ was prepared based on the study of the $\left[\mathrm{W}(\mathrm{CO})_{3} \mathrm{I}_{2}\left(\mathrm{NCCH}_{3}\right)_{2}\right]$ immobilization on Silsesq-TCA, using the following procedure: A mixture of Silsesq-TCA $(2.0 \mathrm{~g})$, and $\left[\mathrm{W}(\mathrm{CO})_{3} \mathrm{I}_{2}\left(\mathrm{NCCH}_{3}\right)_{2}\right](4.46 \mathrm{~g})$ in ethanol $(50 \mathrm{~mL})$ under nitrogen was shaken at room temperature over $12 \mathrm{~h}$. Afterwards, the solvent was eliminated by filtration in nitrogen atmosphere and the new catalyst was washed four times with dichloromethane and ethanol and thus, dried, giving $1.7 \mathrm{~g}$ of Silsesq-TCA- $\left[\left(\mathrm{W}(\mathrm{CO})_{3} \mathrm{I}_{2}\right)_{3}\right]$ (85\% yield), as illustrated in Scheme 1.

\subsubsection{Synthesis of heterogeneous catalyst - Silica-TCA-[W(CO $\left.)_{3} I_{2}\right]$}

The Silica-TCA-[W(CO) $\left.)_{3} \mathrm{I}_{2}\right]$ was also prepared based on the study of the $\left[\mathrm{W}(\mathrm{CO})_{3} \mathrm{I}_{2}\left(\mathrm{NCCH}_{3}\right)_{2}\right]$ immobilization on Silica-TCA, using the following procedure:

About $37.12 \mathrm{~mL}$ of 3-chloropropyltrimethoxysilane were added in a flask containing in $350 \mathrm{~mL}$ of dry toluene and $12 \mathrm{~g}$ silica, the reaction was shaken during $48 \mathrm{~h}$ and under nitrogen atmosphere at $140{ }^{\circ} \mathrm{C}$. After $48 \mathrm{~h}$, the precursor material was filtered and washed repeatedly with ethanol. The precursor material was called 3chloropropyl silica gel (Silica-PrCl).

About $10 \mathrm{~g}$ of Silica-PrCl was added in a solution of $2.0 \mathrm{~g}$ of thiocarbamide dispersed in $0.70 \mathrm{~g}$ of $\mathrm{NaH}$ and in $300 \mathrm{~mL}$ of DMF. The suspension was shaken at $0{ }^{\circ} \mathrm{C}$ for three hours, then the temperature was increased to $80^{\circ} \mathrm{C}$ and was shaken for another $48 \mathrm{~h}$. The intermediate product 3-(thiocarbamide-propyl) silica gel (Silica-TCA), was filtered, washed and heated under vacuum for $10 \mathrm{~h}$.

3-(thiocarbamide-propyl) silica gel (Silica-TCA) (2.0 g), was added to a solution of $\left[\mathrm{W}(\mathrm{CO})_{3} \mathrm{I}_{2}\left(\mathrm{NCCH}_{3}\right)_{2}\right](2.61 \mathrm{~g})$ in pure ethanol $(50 \mathrm{~mL})$ under nitrogen, and the system was shaken at $25^{\circ} \mathrm{C}$ over $12 \mathrm{~h}$. Next, the solvent was eliminated by filtration in nitrogen atmosphere and the new catalyst was washed four times with dichloromethane and ethanol and thus, dried, giving $1.8 \mathrm{~g}$ of SilicaTCA-[W(CO) $\left.)_{3} \mathrm{I}_{2}\right]$ (90\% yield), as illustrated in Scheme 2.

\subsection{Study of immobilization of $\left[\mathrm{W}(\mathrm{CO})_{3} \mathrm{I}_{2}\left(\mathrm{NCCH}_{3}\right)_{2}\right]$ on silicon- based materials}

\subsubsection{Equilibrium time}

The equilibrium times were studied using $120 \mathrm{mg}$ of each material at temperature $298 \mathrm{~K}$ and under nitrogen atmosphere. The initial concentration of the complex $\left[\mathrm{W}(\mathrm{CO})_{3} \mathrm{I}_{2}\left(\mathrm{NCCH}_{3}\right)_{2}\right]$ was $5.0 \times 10^{-3} \mathrm{M}$ in ethanol and solution volume was $50 \mathrm{~mL}$ for both materials. The time intervals were between 5 and $40 \mathrm{~min}$ for both materials, then, the materials were filtrated and the concentrations of tungsten in solution was determined. 
<smiles>CCO[Si](CCCCl)(OCC)OCC</smiles>

CPTES

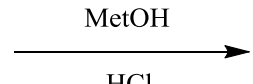

$\mathrm{HCl}$

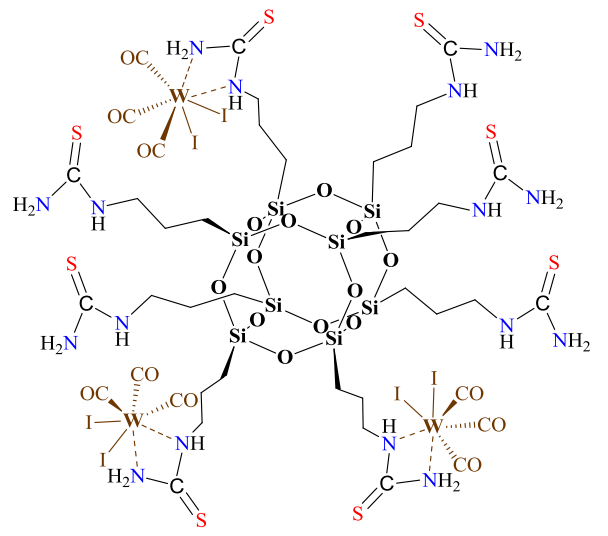

Silsesq-TCA- $\left[\left(\mathrm{W}(\mathrm{CO})_{3} \mathrm{I}_{2}\right)_{3}\right]$

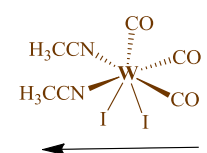<smiles>NC(=S)NCCC[Si]12O[Si]3(CCCNC(N)=S)O[Si]4(CCCNC(N)=S)O[Si](CCCNC(N)=S)(O1)O[Si]1(CCCNC(N)=S)O[Si](CCCNC(N)=S)(O2)O[Si](CCCNC(N)=S)(O3)O[Si](CCCNC(N)=S)(O4)O1</smiles>

Silsesq-TCA

Scheme 1. Synthesis of the Silsesq-TCA-[(W(CO) $\left.\left.)_{3} \mathrm{I}_{2}\right)_{3}\right]$ catalyst.

\subsubsection{Isotherms of immobilization}

The maximum capacities of the Silsesq-TCA and Silica-TCA from ethanolic solutions were investigated at $25{ }^{\circ} \mathrm{C}$ by batch immobilization process under nitrogen atmosphere. Nearly $120 \mathrm{mg}$ of each adsorbent material was added in $50 \mathrm{~mL}$ of solution with different concentrations of complex $\left[\mathrm{W}(\mathrm{CO})_{3} \mathrm{I}_{2}\left(\mathrm{NCCH}_{3}\right)_{2}\right]$ of concentrations between $0.5 \times 10^{-3}$ to $5.0 \times 10^{-3} \mathrm{~mol} / \mathrm{L}$ for Silsesq-TCA and SilicaTCA.

The previous tests showed that the equilibrium was achieved rapidly, about $20 \mathrm{~min}$ for Silsesq-TCA and about $30 \mathrm{~min}$ for SilicaTCA. The mixture was shaken for $25 \mathrm{~min}$ for Silsesq-Pr-TCA and 40 min for Silica-TCA, and then the solids were filtered and the amount of tungsten was analyzed by ICP-MS. The amount of adsorbed complex, $N_{f}$, in each flask was determined by the equation $N_{f}=\left(N_{a}-N_{s}\right) / m$. The sorption capacities of the tungsten complex for both materials were presented as sorption isotherms $\left(N_{f} v s N_{c}\right)$.

\subsubsection{Thermodynamic parameters}

Thermodynamic studies were conducted at temperatures of 25-65 ${ }^{\circ} \mathrm{C}$ under nitrogen atmosphere, maintaining constant the level of the complex, the amount of adsorbent and the time in $50 \mathrm{~mL}, 120 \mathrm{mg}$ and $25 \mathrm{~min}$ for Silsesq-TCA and $50 \mathrm{~mL}, 120 \mathrm{mg}$ and 40 min for Silica-TCA, respectively [17].

\subsection{Chromatographic parameters}

The analyses were obtained through of a gas chromatograph coupled in a mass selective detector (Thermo Scientific) using fused silica capillary column. The carrier gas used was the helium with constant pressure mode of $70 \mathrm{KPa}$. The heating ramp of the oven was programmed varying the temperature from 60 to $200{ }^{\circ} \mathrm{C}$ (held for $2 \mathrm{~min}$ ) at a rate of $50^{\circ} \mathrm{C} / \mathrm{min}$. Samples of $1.5 \mu \mathrm{L}$ were injected in a preheated inlet $\left(250^{\circ} \mathrm{C}\right)$ working in the splitless mode. The mass spectrometer was operated in the full scan mode in the range 30-300. To analyze of the conversion percentages, the proportion between dibutyl ether and the olefins were calculated.

\subsubsection{Catalytic studies}

Silsesq-TCA- $\left[\left(\mathrm{W}(\mathrm{CO})_{3} \mathrm{I}_{2}\right)_{3}\right]$ and Silica-TCA- $\left[\mathrm{W}(\mathrm{CO})_{3} \mathrm{I}_{2}\right]$ were tested in the epoxidation of 1-octene, using tertbutyl hydroperoxide (TBHP) as oxidant at $55^{\circ} \mathrm{C}$ under air atmosphere. The reactions were performed in a container with magnetic stirring and to prevent evaporation of the dichloromethane a condenser was used $[17,18]$. The container was loaded with $10 \mathrm{mmol}$ of 1 -octene, internal standard (Dibutyl ether), $0.1 \mathrm{mmol}$ of homogeneous and heterogeneous catalysts, $20 \mathrm{mmol}$ of oxidant and dichloromethane $[17,18]$. The reactions were initiated with the addition of the oxidant agent (TBHP). The samples were collected every 20 min during the first hour, then every two hours until eight hours and 


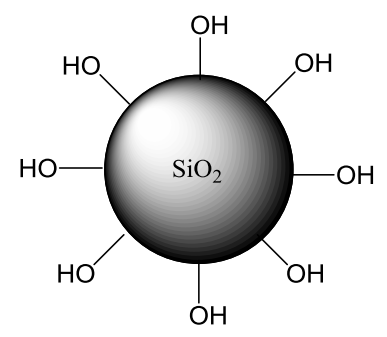

Sílica gel
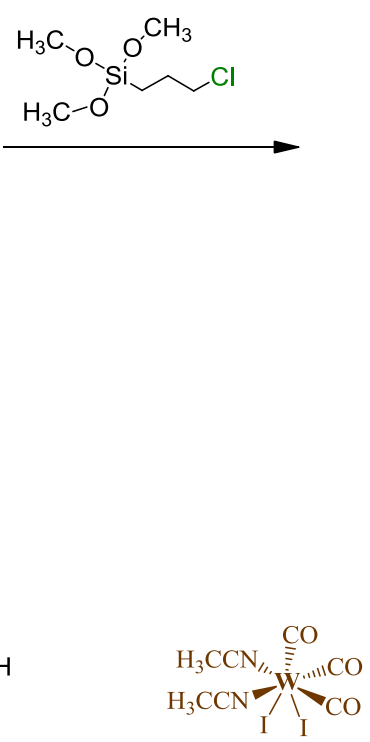

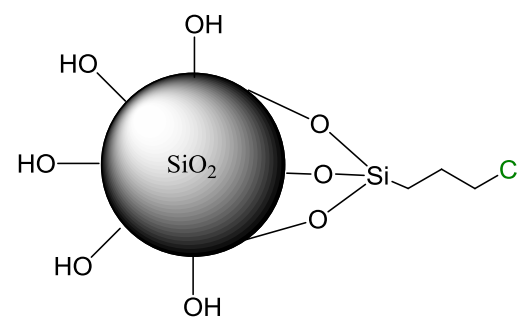

Silica-PrCl<smiles>NC(N)=S</smiles>

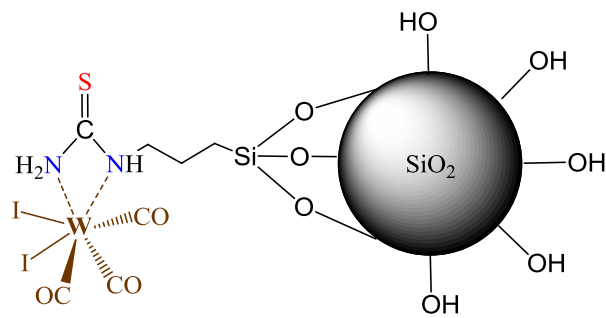

Silica-TCA-[W(CO) $\left.\mathrm{I}_{2}\right]$

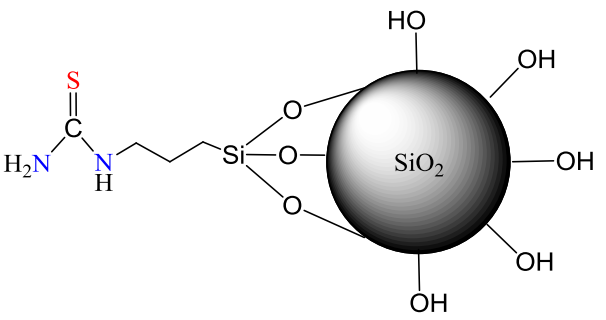

Silica-TCA

Scheme 2. Synthesis of Silica-TCA-[W(CO $\left.)_{3} \mathrm{I}_{2}\right]$ catalyst.

the last in $24 \mathrm{~h}$ of reaction [17,18]. To disable the oxidant agent manganese dioxide was added in each sample collected. The resulting viscous material was separated by filtration and a micro aliquot of the supernatant was injected into the GC-MS. The conversion of each substrate was evaluated by the formation of their respective epoxides in a GC-MS using the previously developed methods. Epoxidation tests without a metal catalyst were investigated and no catalytic activity was observed $[17,18]$.

\section{Results and discussion}

\section{1. $\left[W(\mathrm{CO})_{3} I_{2}\left(\mathrm{NCCH}_{3}\right)_{2}\right],\left[W(\mathrm{CO})_{3} I_{2}(\mathrm{TCA})\right]$, Silsesq-TCA- $\left[\left(\mathrm{W}(\mathrm{CO})_{3} I_{2}\right)_{3}\right]$ and Silica-TCA- $\left[W(\mathrm{CO})_{3} I_{2}\right]$}

The organometallic complex of tungsten $\left[\mathrm{W}(\mathrm{CO})_{3} \mathrm{I}_{2}\left(\mathrm{NCCH}_{3}\right)_{2}\right]$ is one of the most known precursors, because it possesses the advantage of replacement of nitriles with other ligands, due to the high lability of the complex [19]. Thiocarbamide is a chemically interesting compound, because it has coordinating functional groups as a nitrogen ligand that could coordinate to $\left[\mathrm{W}(\mathrm{CO})_{3} \mathrm{I}_{2}\left(\mathrm{NCCH}_{3}\right)_{2}\right]$, affording the stable complex [W(CO) $\left.)_{3} \mathrm{I}_{2}(\mathrm{TCA})\right]$.

Elemental analysis was performed for both organometallic complexes.

$\left[W(\mathrm{CO})_{3} \mathrm{I}_{2}\left(\mathrm{NCCH}_{3}\right)_{2}\right]: \mathrm{O}_{3} \mathrm{C}_{7} \mathrm{H}_{6} \mathrm{~N}_{2} \mathrm{I}_{2} \mathrm{~W}(603.84 \mathrm{~g} / \mathrm{mol})$ : calculated C 13.91\%, H 1.00\%, N 4.63\%; found C 13.66\%, H 0.91\%, N $4.52 \%$.

[W(CO) $\left.)_{3} \mathrm{I}_{2}(\mathrm{TCA})\right]: \mathrm{O}_{3} \mathrm{C}_{4} \mathrm{H}_{4} \mathrm{~N}_{2} \mathrm{SI}_{2} \mathrm{~W}(597.64 \mathrm{~g} / \mathrm{mol})$ : calculated $\mathrm{C}$ 8.03\%, H 0.67\%, N 4.68\%; found C 7.97\%, H 0.59, N 4.56\%. This means that there are $1.67 \mathrm{mmol}$ of thiocarbamide groups per gram of complex $\left[\mathrm{W}(\mathrm{CO})_{3} \mathrm{I}_{2}(\mathrm{TCA})_{2}\right]$.

Silsesq-TCA- $\left[\left(W(C O)_{3} I_{2}\right)_{3}\right]: \quad \mathrm{Si}_{8} \mathrm{O}_{21} \mathrm{C}_{41} \mathrm{H}_{72} \mathrm{~N}_{16} \mathrm{~S}_{8} \mathrm{I}_{6} \mathrm{~W}_{3}(2917.52 \mathrm{~g} /$ mol): calculated C $16.86 \%, \mathrm{~N} 7.67 \%, \mathrm{H} 2.46 \%, \mathrm{~W} 18.90 \%$; found $\mathrm{C}$ $16.56 \%$, N 7.55\%, H 2.16\%, W $18.78 \%$. The resulting product SilsesqTCA- $\left[\left(\mathrm{W}(\mathrm{CO})_{3} \mathrm{I}_{2}\right)_{3}\right]$ contained $18.78 \%$ of tungsten. This value indicates that three tungsten units are bound to the Silsesq-TCA$\left[\left(\mathrm{W}(\mathrm{CO})_{3} \mathrm{I}_{2}\right)_{3}\right]$. The procedure is shown in Scheme 1.

The W loading on Silica-TCA-[W(CO) $\left.{ }_{3} \mathrm{I}_{2}\right]$ was of $8.52 \%$ (Scheme 2). The capacity of anchoring of the complex was determined by ICP-MS and it was found a value of $0.46 \mathrm{mmol}$ of tungsten groups per gram of material Silica-TCA-[W(CO) $\left.)_{3} \mathrm{I}_{2}\right]$.

The FTIR spectrum of $\left[\mathrm{W}(\mathrm{CO})_{3} \mathrm{I}_{2}\left(\mathrm{NCCH}_{3}\right)_{2}\right]$ shows the main absorption bands of the complex, asymmetric $v_{\mathrm{C}} \equiv_{\mathrm{N}}$ bands at 2276 and $2315 \mathrm{~cm}^{-1}$ and an intense stretching $v_{\mathrm{C}} \equiv_{\mathrm{O}}$ at 2095, 1945 and $1880 \mathrm{~cm}^{-1}$.

The FTIR analysis of homogeneous catalyst ([W(CO) $\left.{ }_{3} \mathrm{I}_{2}(\mathrm{TCA})\right]$ ) shows three signals in the region of 2032, 1950 and $1925 \mathrm{~cm}^{-1}$. The $\mathrm{C} \equiv \mathrm{N}$ band has disappeared after reaction with TCA ligand.

On the other hand, the FTIR spectrum of the new catalyst Silsesq-TCA- $\left[\left(\mathrm{W}(\mathrm{CO})_{3} \mathrm{I}_{2}\right)_{3}\right]($ Fig. $1 \mathrm{~A})$ is observed the appearance of new bands in the region of 3446, 2853,1622, 1415, 1111 and $722 \mathrm{~cm}^{-1}$ corresponding to the groups $\mathrm{NH}_{2}, \mathrm{CH}_{2}, \mathrm{NH}, \mathrm{SiCH}_{2}, \mathrm{Si}-\mathrm{O}-\mathrm{Si}$, and $\mathrm{C}=\mathrm{S}$ respectively. The bands $\mathrm{SiCH}_{2}$, and $\mathrm{CH}_{2}$ are derived of the silylating agent 3-chloropropyltriethoxysilane (CPTES), the bands of $\mathrm{NH}_{2}, \mathrm{NH}$ and $\mathrm{C}=\mathrm{S}$ from the molecule of TCA and the deformation band of $\mathrm{Si}$ $\mathrm{O}-\mathrm{Si}$ is characteristic and derived from silsesquioxane. The stretching $v_{\mathrm{C}} \equiv_{\mathrm{O}}$ bands at 2000, 1930 and $1845 \mathrm{~cm}^{-1}$, confirm the immobilization of $\left[\mathrm{W}(\mathrm{CO})_{3}\right]$ on the POSS.

In the spectrum of Silica-TCA- $\left[\mathrm{W}(\mathrm{CO})_{3} \mathrm{I}_{2}\right]$ (Fig. 1B) the absorption bands of $v_{C} \equiv_{O}$ is detected at 2010, 1950 and $1879 \mathrm{~cm}^{-1}$, attesting the coordination of the $\left[\mathrm{W}(\mathrm{CO})_{3}\right]$ on silica gel. These values are also the same as in the homogeneous complex [W(CO) $)_{3} \mathrm{I}_{2}$ (TCA)] [20].

In the ${ }^{13} \mathrm{C}$ NMR spectrum of Silsesq-TCA- $\left[\left(\mathrm{W}(\mathrm{CO})_{3} \mathrm{I}_{2}\right)_{3}\right]$ (Fig. $2 \mathrm{~A}$ ) three peaks are observed in $9.10\left(\mathrm{CH}_{2}-\mathrm{Si}\right)(1), 20.85\left(\mathrm{CH}_{2}-\mathrm{CH}_{2} \mathrm{Si}\right)(2)$, and $39.16 \mathrm{ppm}\left(\mathrm{CH}_{2}-\mathrm{N}\right)$ (3), confirming the anchoring of 3chloropropyltrimethoxysilane. These three peaks were expected since even after a series of reactions the integrity of the organic chain was conserved. The peak at 171.85 ppm (4) region appears 

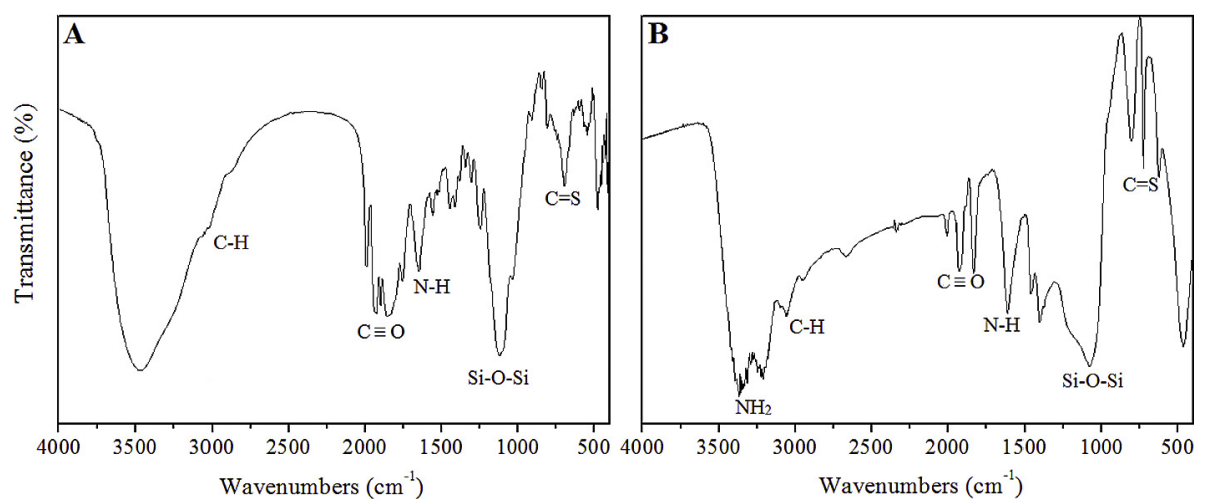

Fig. 1. FTIR spectra of Silsesq-TCA-[(W(CO) $\left.\left.)_{3} \mathrm{I}_{2}\right)_{3}\right](A)$ and Silica-TCA- $\left[\mathrm{W}(\mathrm{CO})_{3} \mathrm{I}_{2}\right](B)$.
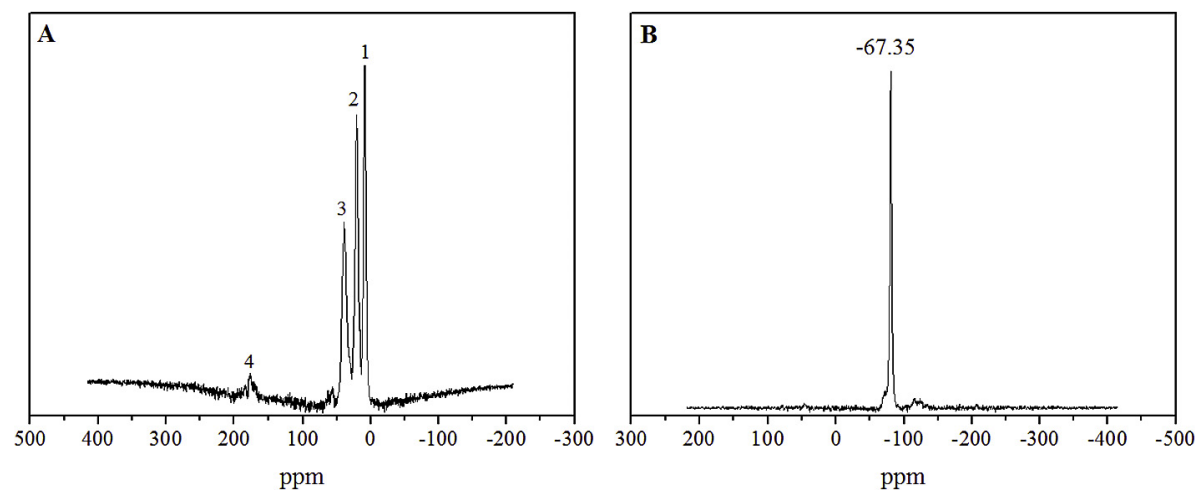

Fig. 2. ${ }^{13} \mathrm{C}$ NMR spectrum of Silsesq-TCA- $\left[\left(\mathrm{W}(\mathrm{CO})_{3} \mathrm{I}_{2}\right)_{3}\right](\mathrm{A})$ and ${ }^{29} \mathrm{Si}$ NMR spectrum of Silsesq-TCA-[(W(CO $\left.\left.)_{3} \mathrm{I}_{2}\right)_{3}\right]$.

due to the incorporation of the molecule of thiocarbamide, this signal is characteristic of the carbon bonded to the sulfur present in the structure of thiocarbamide. After reaction with $\left[\mathrm{W}(\mathrm{CO})_{3} \mathrm{I}_{2}\left(\mathrm{NCCH}_{3}\right)_{2}\right]$ complex the resonances of the carbon atoms of the carbonyl groups of the complex are not apparent [21].

The ${ }^{29} \mathrm{Si}$ NMR solid-state spectrum of Silsesq-TCA-[(W(CO) $\left.\left.)_{3} \mathrm{I}_{2}\right)_{3}\right]$ (Fig. 2B) shows a signal at $\mathrm{d}-67.35 \mathrm{ppm}$, which comes in the range observed for the same compound by other authors $(-66.2$ to -68.0$)$, and is typical of a $\mathrm{T}_{3}$ species $\left[\mathrm{T}^{\mathrm{m}}=\mathrm{RSi}(\mathrm{OSi})_{\mathrm{m}}\left(\mathrm{OR}^{\prime}\right)_{3-\mathrm{m}}\right]$ [22,23].

In the ${ }^{13} \mathrm{C}$ NMR spectrum of Silica-TCA- $\left[\mathrm{W}(\mathrm{CO})_{3} \mathrm{I}_{2}\right]$ (Fig. 3A) three peaks are observed in $8.03\left(\mathrm{CH}_{2}-\mathrm{Si}\right)(1), 19.78\left(\mathrm{CH}_{2}-\mathrm{CH}_{2} \mathrm{Si}\right)(2)$, and $38.86 \mathrm{ppm}\left(\mathrm{CH}_{2}-\mathrm{N}\right)(3)$, which are allocated to the carbon of the chain propyl of the silylating agent. The peak at 169.35 ppm (6) region appears due to the incorporation of the molecule of thiocarbamide. After reaction with the $\left[\mathrm{W}(\mathrm{CO})_{3} \mathrm{I}_{2}\left(\mathrm{NCCH}_{3}\right)_{2}\right]$ the resonances peak of the carbon atoms of the carbonyl groups of the complex are not apparent, due to the absence of proton [21]. The peaks in the region of 56.87 (4) and $61.45 \mathrm{ppm}$ (5) refer to the hydroxyl groups of the silica gel that unreacted during all steps of preparation of catalyst.

The ${ }^{29} \mathrm{Si}$ NMR solid-state spectrum of Silica-TCA-[W(CO $\left.)_{3} \mathrm{I}_{2}\right]$ (Fig. 3B) shows four peaks, the two peaks in -114.42 (1) and $-105.77 \mathrm{ppm}(2)$ are assigned to pure surface signals and are assigned, respectively, to $\mathrm{Si}(\mathrm{O}-\mathrm{Si})_{3} \mathrm{OH}$, corresponding to the $\mathrm{Q}^{3}$ signal; and $\mathrm{Si}(\mathrm{OSi})_{4}$, corresponding to the $\mathrm{Q}^{4}$ signal [24]. The peak at $-71.14 \mathrm{ppm}(3)$ is predicted to $\mathrm{RSi}(\mathrm{OSi})_{3}$ and corresponds to $\mathrm{T}^{3}$ signal. Already the peak at $-61.25 \mathrm{ppm}$ (4) can be assigned to the
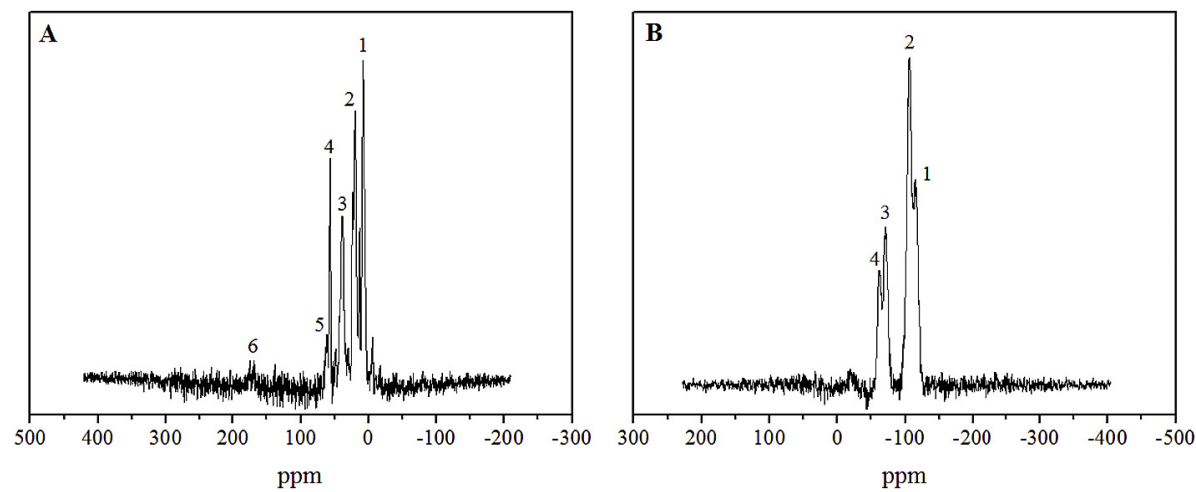

Fig. 3. ${ }^{13} \mathrm{C}$ NMR spectrum of Silica-TCA- $\left[\mathrm{W}(\mathrm{CO})_{3} \mathrm{I}_{2}\right](\mathrm{A})$ and ${ }^{29} \mathrm{Si}$ NMR spectrum of Silica-TCA- $\left[\mathrm{W}(\mathrm{CO})_{3} \mathrm{I}_{2}\right]$. 
silicon atom of the silylating agent linked to a hydroxyl group, forming the structure $\mathrm{RSi}(\mathrm{OSi})(\mathrm{OH})_{2}$. This signal is commonly referred to as $T_{2}$ signal [24,25].

Scanning electron micrographs (SEM) was performed in the heterogeneous catalyst in order to detect differences in their surfaces. The SEM images of Silsesq-TCA- $\left[\left(\mathrm{W}(\mathrm{CO})_{3} \mathrm{I}_{2}\right)_{3}\right]$ and Silica-TCA$\left[\mathrm{W}(\mathrm{CO})_{3} \mathrm{I}_{2}\right]$ are shown in Fig. $4 \mathrm{~A}$ and $\mathrm{B}$. The spheres appearance and size were similar to precursor materials, demonstrating that the surface of silsesquioxane and Silica gel have good mechanical stability and they were not destroyed during the whole reaction [26]. The surface of Silsesq-TCA- $\left[\left(\mathrm{W}(\mathrm{CO})_{3} \mathrm{I}_{2}\right)_{3}\right]$ and Silica-TCA- $\left[\mathrm{W}(\mathrm{CO})_{3} \mathrm{I}_{2}\right]$ have more clusters than their starting materials. Apparently, the surface of precursor materials was smooth and became rough after the modification reactions.

The exact superficial areas of the Silsesq-TCA- $\left[\left(\mathrm{W}(\mathrm{CO})_{3} \mathrm{I}_{2}\right)_{3}\right]$ and Silica-TCA- $\left[\mathrm{W}(\mathrm{CO})_{3} \mathrm{I}_{2}\right]$ were estimated by BET method (Table 1 ).

The relatively small value of the $S_{B E T}$ for the Silsesq-TCA$\left[\left(\mathrm{W}(\mathrm{CO})_{3} \mathrm{I}_{2}\right)_{3}\right]$ is not estimated, since that the cubic silica core has a diameter of $0.53 \mathrm{~nm}$ and a spherical radius of $1-3 \mathrm{~nm}$ containing peripheral organic units [27]. The slow value of the $S_{\mathrm{BET}}$ of the Silsesq-TCA- $\left[\left(\mathrm{W}(\mathrm{CO})_{3} \mathrm{I}_{2}\right)_{3}\right]$ could have been affected by the propensity of the particles to form clusters [27]. The Silsesq-TCA$\left[\left(\mathrm{W}(\mathrm{CO})_{3} \mathrm{I}_{2}\right)_{3}\right]$ has type IV isotherm shape with $\mathrm{H} 1$ hysteresis [27], typical of solids made by clusters of spherical particles of uniform size and shape. This feature is fairly typical of mesoporous solids with pore diameters in the range $2-50 \mathrm{~nm}$. The absence of any micropores, the calculated average pore diameter and the relatively small $\mathrm{S}_{\mathrm{BET}}$ value are in agreement with these observations.

The Silica-TCA-[W(CO) $\left.{ }_{3} \mathrm{I}_{2}\right]$ has type IV isotherm shape with a hysteresis loop style $\mathrm{H} 3$ [27], demonstrating that the pore dimension and shape are not well clear. This feature is frequently found for mesoporous solids containing clusters of spherical particles of fairly constant size and array, which give rise to piping pores presenting minor disparities of the cross-section along the longitudinal way.

\subsection{Immobilization study of $\left[W(\mathrm{CO})_{3} \mathrm{I}_{2}\left(\mathrm{NCCH}_{3}\right)_{2}\right]$ on silicon-based materials}

\subsubsection{Immobilization isotherms of organometallic complexes}

Initially, some solvents were tested in immobilization processes, such as, methanol, ethanol, water, hexane and dichloromethane. The ethanol showed the best behavior. Then, it was adopted as the medium to be used in immobilization experiments. Preliminary tests showed that the systems achieve the equilibrium condition with a quantity of adsorbent of $120 \mathrm{mg}$ for both adsorbents.

Fig. $5 \mathrm{~A}$ shows the effects of contact time for immobilization of $\left[\mathrm{W}(\mathrm{CO})_{3} \mathrm{I}_{2}\left(\mathrm{NCCH}_{3}\right)_{2}\right]$ on Silsesq-TCA and Silica-TCA at $25{ }^{\circ} \mathrm{C}$ in ethanol solution. The systems achieved the equilibrium condition with a contact time of approximately 20 and $30 \mathrm{~min}$ for Silsesq-TCA and Silica-TCA, respectively. The immobilization rate of the SilsesqTCA was faster than the Silica-TCA due to the immobilization sites

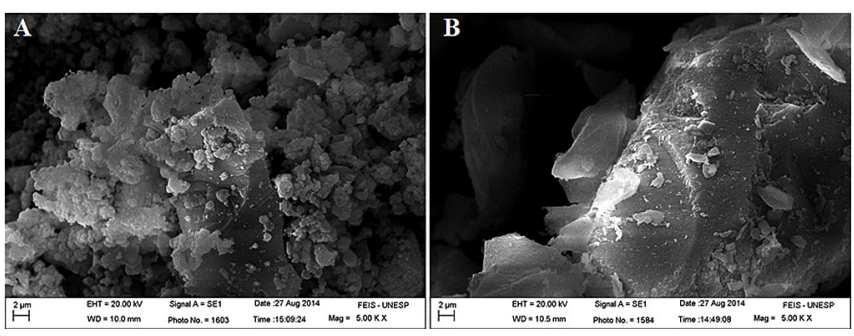

Fig. 4. SEM images for Silsesq-TCA-[(W(CO) $\left.\left.{ }_{3} \mathrm{I}_{2}\right)_{3}\right](\mathrm{A})$ and Silica-TCA- $\left[\mathrm{W}(\mathrm{CO})_{3} \mathrm{I}_{2}\right](\mathrm{B})$. are much more exposed on the surface of this kind of material. The eight (thiocarbamide)propyl groups are anchored in the eight vertices of the outer surface of the silsesquioxane cube. Additionally, the silica gel has the great majority of (thiocarbamide)propyl groups anchored on the inner surface of the pores [28,29].

To investigate the immobilization capacity, a range of concentrations of the $\left[\mathrm{W}(\mathrm{CO})_{3} \mathrm{I}_{2}\left(\mathrm{NCCH}_{3}\right)_{2}\right]$ in ethanol solution was shaken for $25 \mathrm{~min}$ for Silsesq-TCA and $40 \mathrm{~min}$ for Silica-TCA, using $120 \mathrm{mg}$ of adsorbent at $25{ }^{\circ} \mathrm{C}$. The maximum immobilization capacity values for $\left[\mathrm{W}(\mathrm{CO})_{3} \mathrm{I}_{2}\left(\mathrm{NCCH}_{3}\right)_{2}\right]$ in ethanol solution, using SilsesqTCA and Silica-TCA, were 1.04 and $0.45 \mathrm{mmol} \mathrm{g}^{-1}$, respectively.

The immobilization isotherms of the organometallic complex for each material are presented in Fig. 5B. The highest values of immobilization of organometallic complex provided by Silsesq-TCA in relation to the Silica-TCA, could not be explained only by the porous structures of both materials. The greater immobilization of Silsesq-TCA could be better explained due to its larger degree of organofunctionalization. The densities of organofunctionalization of Silsesq-TCA and Silica-TCA were 5.86 and $2.14 \mathrm{mmol}$ of (thiocarbamide)propyl groups per gram, respectively.

To estimate the effect of temperature, the immobilization tests were executed at five different temperatures $(25,35,45,55$ and $65{ }^{\circ} \mathrm{C}$ ). In Fig. 5C, the adsorption processes were favoured with increasing temperature, which demonstrates that the adsorption of the complex is an endothermic process.

\subsubsection{Applications of isotherm models}

From Fig. 5B it is possible to apply the isothermal models such as Langmuir [30], Freundlich [31,32], Temkin [33] and DubininRadushchevich (D-R) [34]. The theoretical data for each model are listed in Table 2.

The Langmuir model emphasizes that the immobilization of the tungsten complex was in monolayers (homogeneous) and the anchoring the complex occurred due to the lability of acetonitrile with the atoms of nitrogen spread around the surface of the materials. It was verified also that the values of $R_{L}$ (Table 2) were smaller than 1 demonstrating that the immobilization of the complex was favorable.

The parameters of the Freundlich model are shown in Table 2. The parameter $n$ greater than 1 reflects an immobilization in multilayered (heterogeneous) of the organometallic complex [31,32,35].

The $E$ values obtained from the D-R model [29] (Table 2) for immobilization of the $\left[\mathrm{W}(\mathrm{CO})_{3} \mathrm{I}_{2}\left(\mathrm{NCCH}_{3}\right)_{2}\right]$ on Silsesq-TCA and Silica-TCA were superior than $8 \mathrm{~kJ} / \mathrm{mol}^{-1}$, where it can be said that the immobilization of the complex was achieved by chemisorption for both materials.

Taking into account the values of the determination factors $\left(R^{2}\right)$ it is notable that the order that best fits the experimental data were Langmuir $>$ Temkin $>$ Freundlich $>$ D-R for Silsesq-TCA and Langmuir $>$ D-R $>$ Temkin $>$ Freundlich for Silica-TCA.

The values of pseudo-first-order, pseudo-second-order and Elovich [36,37] are given in Table 3. Elovich model was the most appropriate to define the kinetic data. The determination factor of Elovich was $\geq 0.998$ for both materials.

Thermodynamic parameters [38] were listed in Table 4. The negative values of $\Delta G$ indicated the spontaneous natures of immobilization of complex on the surface of Silsesq-TCA and SilicaTCA. The positive values of enthalpy change $(\Delta H)$ showed the sorptions are endothermic. The positive values of $\Delta S$ resulted from the increased randomness due to the sorption of organometallic complex.

\subsection{Activity catalytic}

The activity of the W-derivatized silsesquioxane and silica gel 
Table 1

Physical parameters of Silsesq-TCA- $\left[\left(\mathrm{W}(\mathrm{CO})_{3} \mathrm{I}_{2}\right)_{3}\right]$ and Silica-TCA- $\left[\mathrm{W}(\mathrm{CO})_{3} \mathrm{I}_{2}\right]$.

\begin{tabular}{lll}
\hline Parameters & Silsesq-TCA- $\left[\left(\mathrm{W}(\mathrm{CO})_{3} \mathrm{I}_{2}\right)_{3}\right]$ & Silica-TCA-[W(CO $\left.)_{3} \mathrm{I}_{2}\right]$ \\
\hline BET surface area, $\mathrm{S}_{\mathrm{BET}}\left(\mathrm{m}^{2} \mathrm{~g}^{-1}\right)$ & 96 & 675 \\
Total pore volume, $\mathrm{Vp}\left(\mathrm{cm}^{3} \mathrm{~g}^{-1}\right)$ & 0.61 & 0.35 \\
Average pore diameter, $\mathrm{D}(\mathrm{nm})$ & 410 & 52 \\
\hline
\end{tabular}
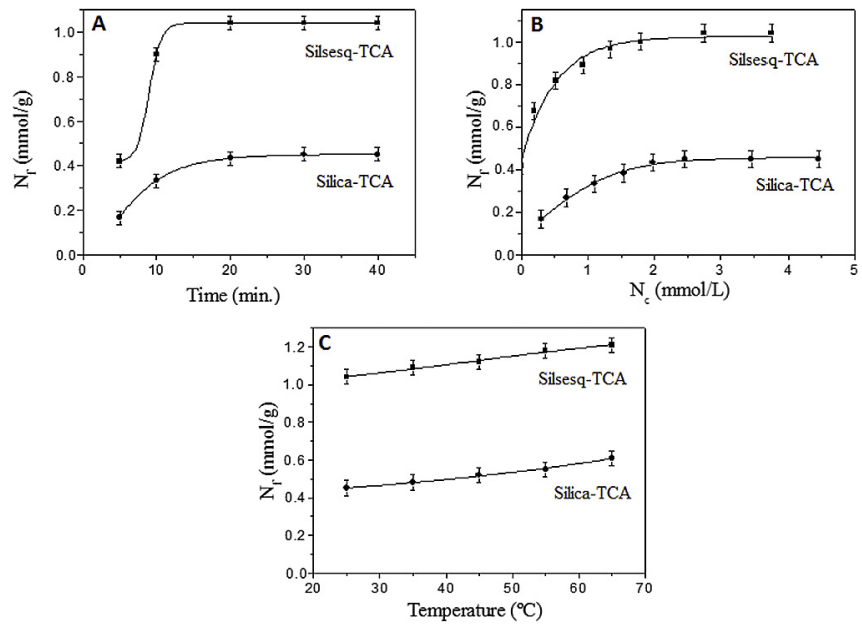

Fig. 5. Isotherms A - Effect of equilibrion time, Isotherms B - Effect of concentration isotherm, and Isotherms $\mathrm{C}$ - Effect of temperature on the adsorption of the $\left[\mathrm{W}(\mathrm{CO})_{3} \mathrm{I}_{2}\left(\mathrm{NCCH}_{3}\right)_{2}\right]$.

Table 2

Isotherm parameters for sorption of organometallic complex in ethanol at $25^{\circ} \mathrm{C}$.

\begin{tabular}{|c|c|c|c|}
\hline Adsorbent & Models & Parameters & {$\left[\mathrm{W}(\mathrm{CO})_{3} \mathrm{I}_{2}\left(\mathrm{NCCH}_{3}\right)_{2}\right]$} \\
\hline \multirow[t]{14}{*}{ Silsesq-TCA } & \multirow[t]{4}{*}{ Langmuir } & $\mathrm{N}_{\mathrm{f}}(\mathrm{mmol} / \mathrm{g})$ & 1.07 \\
\hline & & $\mathrm{b}(\mathrm{L} / \mathrm{mmol})$ & 8.94 \\
\hline & & $\mathrm{R}_{\mathrm{L}}$ & 0.02 \\
\hline & & $\mathbf{R}^{2}$ & 0.998 \\
\hline & \multirow[t]{3}{*}{ Freundlich } & $\mathrm{n}(\mathrm{mol} / \mathrm{L})$ & 0.15 \\
\hline & & $\mathrm{K}_{\mathrm{F}}(\mathrm{mmol} / \mathrm{g})$ & 1.12 \\
\hline & & $\mathbf{R}^{2}$ & 0.967 \\
\hline & \multirow[t]{3}{*}{ Temkin } & $\mathrm{A}(\mathrm{L} / \mathrm{mmol})$ & 10.11 \\
\hline & & $\mathrm{B}$ & 0.13 \\
\hline & & $\mathbf{R}^{2}$ & 0.978 \\
\hline & \multirow[t]{4}{*}{$\mathrm{D}-\mathrm{R}$} & $\mathrm{N}_{\mathrm{f}}^{\max }(\mathrm{mmol} / \mathrm{g})$ & 1.01 \\
\hline & & $\mathrm{B}_{1}$ & 0.06 \\
\hline & & $\mathrm{E}(\mathrm{Kj} / \mathrm{mol})$ & 11.78 \\
\hline & & $\mathbf{R}^{2}$ & 0.922 \\
\hline \multirow[t]{14}{*}{ Silica-TCA } & \multirow[t]{4}{*}{ Langmuir } & $\mathrm{N}_{\mathrm{f}}(\mathrm{mmol} / \mathrm{g})$ & 0.52 \\
\hline & & $\mathrm{b}(\mathrm{L} / \mathrm{mmol})$ & 1.75 \\
\hline & & $\mathrm{R}_{\mathrm{L}}$ & 0.10 \\
\hline & & $\mathbf{R}^{2}$ & 0.993 \\
\hline & \multirow[t]{3}{*}{ Freundlich } & $\mathrm{n}(\mathrm{mol} / \mathrm{L})$ & 0.10 \\
\hline & & $\mathrm{K}_{\mathrm{F}}(\mathrm{mmol} / \mathrm{g})$ & 1.39 \\
\hline & & $\mathbf{R}^{2}$ & 0.860 \\
\hline & \multirow[t]{3}{*}{ Temkin } & $\mathrm{A}(\mathrm{L} / \mathrm{mmol})$ & 8.67 \\
\hline & & $\mathrm{B}$ & 0.28 \\
\hline & & $\mathbf{R}^{2}$ & 0.879 \\
\hline & \multirow[t]{4}{*}{ D-R } & $\mathrm{N}_{\mathrm{f}}^{\max }(\mathrm{mmol} / \mathrm{g})$ & 2.11 \\
\hline & & $\mathrm{B}_{1}$ & 0.08 \\
\hline & & $\mathrm{E}(\mathrm{Kj} / \mathrm{mol})$ & 8.83 \\
\hline & & $\mathbf{R}^{2}$ & 0.974 \\
\hline
\end{tabular}

(Silsesq-TCA- $\left[\left(\mathrm{W}(\mathrm{CO})_{3} \mathrm{I}_{2}\right)_{3}\right]$ and Silica-TCA- $\left[\mathrm{W}(\mathrm{CO})_{3} \mathrm{I}_{2}\right]$, respectively) as a catalyst precursor for the epoxidation of olefin were investigated for 1-octene. The same study was performed using the catalyst $\left[\mathrm{W}(\mathrm{CO})_{3} \mathrm{I}_{2}(\mathrm{TCA})\right]$. The results given in Table 5 show that both mesoporous catalysts Silsesq-TCA- $\left[\left(\mathrm{W}(\mathrm{CO})_{3} \mathrm{I}_{2}\right)_{3}\right]$ and SilicaTCA- $\left[\mathrm{W}(\mathrm{CO})_{3} \mathrm{I}_{2}\right]$ achieve similar catalytic conversions in the oxidation of 1 -octene (72 and $68 \%$, respectively); however, the conversion of 1 -octene for homogeneous catalyst $\left[\mathrm{W}(\mathrm{CO})_{3} \mathrm{I}_{2}\right.$ (TCA)] is a little bigger. This is due to the fact that homogeneous catalysts have advantages over the heterogeneous, in particular greater selectivity and yield [18]. However, the facility with which in the heterogeneous processes products are separated and recycled, render these preferred by industry [18].

Therefore, the results presented in Table 5 shows that the heterogeneous catalysts studied in this paper combine the advantages of both types of catalysts. The same behavior was observed in the TOF values, according to the following order: $\left[\mathrm{W}(\mathrm{CO})_{3} \mathrm{I}_{2}\right.$ (TCA)] $\left(96 \mathrm{~mol}\right.$ of $\left.\mathrm{W}^{-1} \mathrm{~h}^{-1}\right)$, Silsesq-TCA-[(W(CO) $\left.\left.)_{3} \mathrm{I}_{2}\right)_{3}\right]\left(86 \mathrm{~mol}\right.$ of $\mathrm{W}^{-1}$ $\left.\mathrm{h}^{-1}\right)$ and Silica-TCA-[W(CO) $\left.\mathrm{I}_{2}\right]\left(79 \mathrm{~mol}\right.$ of $\left.\mathrm{W}^{-1} \mathrm{~h}^{-1}\right)$. In the epoxidation of 1-octene are identified two products referred to as 1octanal and 1,2-epoxyoctane. Silsesq-TCA- $\left[\left(\mathrm{W}(\mathrm{CO})_{3} \mathrm{I}_{2}\right)_{3}\right]$ has a satisfactory selectivity for formation of 1,2 -epoxyoctane, $88 \%$ versus $12 \%$ for the formation of 1-octanal, whereas the Silica-TCA[W(CO $\left.)_{3} \mathrm{I}_{2}\right]$ has a good selectivity, $91 \%$ for 1,2-epoxyoctane and $9 \%$ for 1-octanal. On the other hand, the selectivity of the homogeneous catalyst $\left[\mathrm{W}(\mathrm{CO})_{3} \mathrm{I}_{2}\right.$ (TCA)] increases for $92 \%$ in epoxy against $8 \%$ for 1-octanal.

Table 6 shows the comparison of the catalysts prepared in this work with other types of catalysts related in the literature for the epoxidation of 1-octene. As can be seen Silsesq-TCA- $\left[\left(\mathrm{W}(\mathrm{CO})_{3} \mathrm{I}_{2}\right)_{3}\right]$ and Silica-TCA-[W(CO) $\left.)_{3} \mathrm{I}_{2}\right]$ have similar conversion capacity that their analogue not supported $\left[\mathrm{W}(\mathrm{CO})_{3} \mathrm{I}_{2}(\mathrm{TCA})\right]$, and show higher conversion values than other types of catalysts in the epoxidation of 1-octene.

The advantage of newly synthesized catalytic materials is not only limited in the percentage conversion. The superiority of these catalysts based on silicon over those previously reported in the literature consists also in isolation of products of high purity with excellent yields, good reaction times, simple product separation procedure and reusability of the catalyst.

\subsubsection{Study of leaching and stability}

The recovery and reusability of the supported Silsesq-TCA$\left[\left(\mathrm{W}(\mathrm{CO})_{3} \mathrm{I}_{2}\right)_{3}\right]$ and Silica-TCA-[W(CO) $\left.)_{3} \mathrm{I}_{2}\right]$ catalysts were investigated in the successive epoxidation of 1-octene with TBHP as oxidant. After the first cycle the solid was separated by simple filtration, washed with dichloromethane and dried at $60{ }^{\circ} \mathrm{C}$ for reuse. The filtrates were utilized for measurement the catalysts leaching. The results displayed that only minor amounts of $\mathrm{W}$ catalysts were leached after the first cycle and no trace of tungsten was detected in the other cycles. As can be seen in Table 7, there was a reduction in the catalytic activity of the first to the second cycle, however, the other cycles tend to remain constant for the both catalysts and no $\mathrm{W}$ was detected after second cycle in the reaction mixture. This may be due to the release of the surface adsorbed $\mathrm{W}$ species. Also, the catalytic behavior of the separated liquid was tested by addition of fresh olefin to the filtrates after each cycle. The oxidation reaction under the same reaction conditions as when the catalyst was utilized showed that the found results are the equivalent as blank experiments.

The FTIR spectra of recycled heterogeneous catalysts showed no major change in comparison with the fresh catalysts. The 
Table 3

Kinetic sorption parameters obtained using pseudo-first-order, pseudo-second-order, and Elovich models for $\left[\mathrm{W}(\mathrm{CO})_{3} \mathrm{I}_{2}(\mathrm{NCCH})_{2}\right]$.

\begin{tabular}{|c|c|c|c|c|c|c|c|c|c|c|}
\hline \multirow[t]{2}{*}{ Sorbent } & \multirow{2}{*}{$\begin{array}{l}\mathrm{N}_{\mathrm{f}}^{\exp } \\
(\mathrm{mmol} / \mathrm{g})\end{array}$} & \multicolumn{3}{|c|}{ Pseudo-first-order } & \multicolumn{3}{|c|}{ Pseudo-second-order } & \multicolumn{3}{|l|}{ Elovich } \\
\hline & & $\begin{array}{l}\mathrm{N}_{\mathrm{f}}^{\max } \\
(\mathrm{mmol} / \mathrm{g})\end{array}$ & $\begin{array}{l}K_{1} \\
\left(\min ^{-1}\right)\end{array}$ & $R^{2}$ & $\begin{array}{l}\mathrm{N}_{\mathrm{f}}^{\max } \\
(\mathrm{mmol} / \mathrm{g})\end{array}$ & $\begin{array}{l}K_{2} \\
\left(\min ^{-1}\right)\end{array}$ & $r^{2}$ & $\begin{array}{l}\alpha \\
(\mathrm{mmol} / \mathrm{gmin})\end{array}$ & $\begin{array}{l}\text { B } \\
(\mathrm{g} / \mathrm{mmol})\end{array}$ & $R^{2}$ \\
\hline Silsesq-TCA & 1.04 & 0.54 & $2.24 \times 10^{-3}$ & 0.897 & 0.62 & 3.357 & 0.942 & 4.428 & 1.574 & 0.999 \\
\hline Silica-TCA & 0.45 & 0.22 & $1.55 \times 10^{-3}$ & 0.901 & 0.56 & 1.421 & 0.953 & 3.875 & 1.187 & 0.998 \\
\hline
\end{tabular}

Table 4

Thermodynamic parameters for $\left[\mathrm{W}(\mathrm{CO})_{3} \mathrm{I}_{2}\left(\mathrm{NCCH}_{3}\right)_{2}\right]$ in ethanol.

\begin{tabular}{lllll}
\hline Sorbent & $\begin{array}{l}\mathrm{t}^{*} \\
\left({ }^{\circ} \mathrm{C}\right)\end{array}$ & $\begin{array}{l}\Delta \mathrm{G}^{\circ} \\
(\mathrm{KJ} / \mathrm{mol})\end{array}$ & $\begin{array}{l}\Delta \mathrm{S}^{\circ} \\
\left(\mathrm{J} / \mathrm{mol} \mathrm{k}^{-1}\right)\end{array}$ & $\begin{array}{l}\Delta \mathrm{H}^{\circ} \\
(\mathrm{KJ} / \mathrm{mol})\end{array}$ \\
\hline Silsesq-TCA & 25 & -37.349 & 125.497 & 48.395 \\
& 35 & -38.604 & & \\
& 45 & -39.859 & & \\
Silica-TCA & 55 & -41.114 & & 34.985 \\
& 65 & -42.369 & & \\
& 25 & -28.171 & 94.652 & \\
& 35 & -29.117 & & \\
& 45 & -30.064 & & \\
& 55 & -31.010 & & \\
& 65 & -31.957 & & \\
& & & & \\
& & & & \\
& 55 & & \\
\end{tabular}

* = Temperature.

absorption bands of $v_{\mathrm{C} \equiv \mathrm{O}}$ are detected at 2020,1950 and $1878 \mathrm{~cm}^{-1}$ for Silsesq-TCA- $\left[\left(\mathrm{W}(\mathrm{CO})_{3} \mathrm{I}_{2}\right)_{3}\right]$ and at 2095,1988 and $1892 \mathrm{~cm}^{-1}$ for Silica-TCA-[W(CO $\left.)_{3} \mathrm{I}_{2}\right]$ confirming the strong coordination of $\left[\mathrm{W}(\mathrm{CO})_{3}\right]$ complex on the silicate materials.

The $\mathrm{W}$ loading on the Silsesq-TCA- $\left[\left(\mathrm{W}(\mathrm{CO})_{3} \mathrm{I}_{2}\right)_{3}\right]$ and Silica-TCA[W(CO) $\left.)_{3} \mathrm{I}_{2}\right]$ were 18.55 and $8.35 \%$ respectively. The capacity of anchoring of the complex was determined by ICP-MS and it was found a value of $1.01 \mathrm{mmol}$ corresponding to about $98.8 \%$ of the starting value for the Silsesq-TCA- $\left[\left(\mathrm{W}(\mathrm{CO})_{3} \mathrm{I}_{2}\right)_{3}\right]$, whereas for SilicaTCA- $\left[\mathrm{W}(\mathrm{CO})_{3} \mathrm{I}_{2}\right]$, the tungsten loading was $98 \%$ corresponding to $0.454 \mathrm{mmol}$ after five cycles.

\section{Conclusions}

The $\left[\mathrm{W}(\mathrm{CO})_{3} \mathrm{I}_{2}\left(\mathrm{NCCH}_{3}\right)_{2}\right]$ complex was immobilized on two

Table 5

Conversions and Turnover Frequencies (TOF) for epoxidation of 1-Octene promoted by Silsesq-TCA- $\left[\left(\mathrm{W}(\mathrm{CO})_{3} \mathrm{I}_{2}\right)_{3}\right]$, Silica-TCA-[W(CO) $\left.)_{3} \mathrm{I}_{2}\right]$ and $\left[\mathrm{W}(\mathrm{CO})_{3} \mathrm{I}_{2}(\mathrm{TCA})\right]$ in the presence of TBHP.

\begin{tabular}{llll}
\hline Catalytic precursor & Substrate & Conversion $^{\mathrm{a}}(\%)$ & TOF $^{\mathrm{b}}$ \\
\hline Silsesq-TCA- $\left[\left(\mathrm{W}(\mathrm{CO})_{3} \mathrm{I}_{2}\right)_{3}\right]$ & 1-Octene & 72 & 86 \\
Silica-TCA- $\left[\mathrm{W}(\mathrm{CO})_{3} \mathrm{I}_{2}\right]$ & & 68 & 79 \\
{$\left[\mathrm{~W}(\mathrm{CO})_{3} \mathrm{I}_{2}(\mathrm{TCA})\right]$} & & 76 & 96 \\
\hline
\end{tabular}

${ }^{\mathrm{a}}$ Conversion at $24 \mathrm{~h}$.

b In units of $\mathrm{mol}(\mathrm{mol} \text { of } \mathrm{W})^{-1} \mathrm{~h}^{-1}$.

Table 6

Comparison of the conversion capacity of Silsesq-TCA- $\left[\left(\mathrm{W}(\mathrm{CO})_{3} \mathrm{I}_{2}\right)_{3}\right]$ and Silica-TCA$\left[\mathrm{W}(\mathrm{CO})_{3} \mathrm{I}_{2}\right]$ with different catalysts in the epoxidation of 1-octene.

\begin{tabular}{llll}
\hline Catalysts & Oxidant & Conv. $^{\text {a }}$ & Ref. \\
\hline Silsesq-TCA- $\left[\left(\mathrm{W}(\mathrm{CO})_{3} \mathrm{I}_{2}\right)_{3}\right]$ & TBHP & 72 & This work \\
Silica-TCA-[W(CO $\left.)_{3} \mathrm{I}_{2}\right]$ & TBHP & 68 & This work \\
{$\left[\mathrm{W}(\mathrm{CO})_{3} \mathrm{I}_{2}(\mathrm{TCA})\right]$} & TBHP & 76 & This work \\
$\mathrm{MCM}-\left[\mathrm{WBr}_{2}(\mathrm{CO})_{3}\left(\mathrm{C}_{2} \mathrm{H}_{3} \mathrm{~N}_{3} \mathrm{~S}\right)_{2}\right]$ & TBHP & 10.4 & {$[21]$} \\
$\mathrm{Mo}^{(\mathrm{VI})} \mathrm{Cl}_{2} \mathrm{O}_{2} \mathrm{Bipy}$ & Molecular $\mathrm{O}_{2}$ & 55 & {$[39]$} \\
POSS-SB-Mo & TBHP & 35 & {$[40]$} \\
POSS-DIM3-CIM5-PW & $\mathrm{H}_{2} \mathrm{O}_{2}$ & 56 & {$[41]$} \\
V-AFBNPs & TBHP & 58 & {$[42]$} \\
{$\left[\mathrm{MoO}_{2} \mathrm{~L}(\mathrm{EtOH})\right]$} & TBHP & 64 & {$[43]$} \\
\hline
\end{tabular}

\footnotetext{
${ }^{\text {a }}$ Conversion (\%).
}

Table 7

Recycling studies performed over Silsesq-TCA- $\left[\left(\mathrm{W}(\mathrm{CO})_{3} \mathrm{I}_{2}\right)_{3}\right]$ and Silica-TCA$\left[\mathrm{W}(\mathrm{CO})_{3} \mathrm{I}_{2}\right]$ catalysts.

\begin{tabular}{lll}
\hline \multirow{2}{*}{ Catalyst } & \multicolumn{2}{l}{ 1-octene } \\
\cline { 2 - 3 } & Conversion $(\%)$ & Selectivity to epoxide $(\%)$ \\
\hline Silsesq-TCA- $\left[\left(\mathrm{W}(\mathrm{CO})_{3} \mathrm{I}_{2}\right)_{3}\right]$ & \\
$1^{\circ}$ cycle & 72 & $88^{\mathrm{a}}$ \\
$2^{\circ}$ cycle & 67 & $87^{\mathrm{a}}$ \\
$3^{\circ}$ cycle & 66 & $87^{\mathrm{a}}$ \\
$4^{\circ}$ cycle & 65 & $86^{\mathrm{a}}$ \\
$5^{\circ}$ cycle & 65 & $87^{\mathrm{a}}$ \\
Silica-TCA- $\left[\mathrm{W}(\mathrm{CO})_{3} \mathrm{I}_{2}\right]$ & \\
$1^{\circ}$ cycle & 68 & $91^{\mathrm{a}}$ \\
$2^{\circ}$ cycle & 65 & $91^{\mathrm{a}}$ \\
$3^{\circ}$ cycle & 65 & $91^{\mathrm{a}}$ \\
$4^{\circ}$ cycle & 64 & $90^{\mathrm{a}}$ \\
$5^{\circ}$ cycle & 64 & $91^{\mathrm{a}}$ \\
\hline
\end{tabular}

a 1,2-Epoxyoctane.

silicate materials, modified with thiocarbamide, resulting in two heterogenized catalysts that were employed as highly efficient catalysts for epoxidation of 1-octene using TBHP as oxidant.

The sorption properties of the Silsesq-TCA and Silica-TCA showed to be dependent of the contact time, concentration and temperature.

The Langmuir and Elovich models were the most suitable to describe the experimental data, emphasizing that the immobilization of the organometallic complex on the catalytic materials were in monolayer and by chemisorption respectively.

Silsesq-TCA- $\left[\left(\mathrm{W}(\mathrm{CO})_{3} \mathrm{I}_{2}\right)_{3}\right]$ and Silica-TCA- $\left[\mathrm{W}(\mathrm{CO})_{3} \mathrm{I}_{2}\right]$ show a high selectivity for epoxide when 1-octene olefin is used.

Silsesq-TCA- $\left[\left(\mathrm{W}(\mathrm{CO})_{3} \mathrm{I}_{2}\right)_{3}\right]$ showed a better conversion and TOF when compared with Silica-TCA-[W(CO $\left.)_{3} \mathrm{I}_{2}\right]$, however, the selectivity to epoxide using Silica-TCA-[W(CO $\left.)_{3} \mathrm{I}_{2}\right]$ was slightly higher.

The similar catalytic activities between heterogeneous catalysts and homogeneous species indicate that the advantages of the homogeneous systems, such as high conversion and selectivity, associated with ease of separation and recycling of the catalysts were achieved.

The reusability of these catalysts was also investigated. The obtained catalysts can be reused for at least five cycles with a slight decrease in their catalytic activity.

\section{Conflict of interest statement}

The authors declare no competing financial interest.

\section{Acknowledgments}

Newton Luiz Dias Filho is grateful for the financial support by the FAPESP-Fundação de Amparo a Pesquisa do Estado de São Paulo (Grant no 2013/24602-0), and the CNPq-Conselho Nacional de Desenvolvimento Científico e Tecnológico (Grant no 306265/20133 and 448168/2014-6).

Eduardo G. Vieira thanks FAPESP-Fundação de Amparo à Pesquisa do Estado de São Paulo (Grant no 2014/05566-5) by partial 
funding.

Newton Luiz Dias Filho and Eduardo G. Vieira acknowledge Professor Enes Furlani Junior, of the Department of plant science, food technology and social economy of Unesp-FEIS by analysis of ICP-MS and GC-MS.

\section{References}

[1] X. Song, W. Zhu, K. Li, J. Wang, H. Niu, H. Gao, W. Gao, W. Zhang, J. Yu, M. Jia, Epoxidation of olefins with oxygen/isobutyraldehyde over transition-metalsubstituted phosphomolybdic acid on SBA-15, Catal. Today 259 (2016) 59-65.

[2] Y.K. Ooi, L. Yuliati, D. Hartanto, H. Nur, S.L. Lee, Mesostructured TUD-C supported molybdena doped titania as high selective oxidative catalyst for olefins epoxidation at ambient condition, Micropor. Mesopor. Mater. 225 (2016) 411-420.

[3] J.H. Clark, D.J. Macquarrie, Handbook of Green Chemistry \& Technology, Blackwell Science Ltd., Oxford, 2002.

[4] J. Hagen, Industrial Catalysis: a Practical Approach, second ed., Wiley-VCH Verlag GmbH \& Co. KGaA, Weinheim, 2006.

[5] J.D. Xu, K.T. Zhu, X.F. Weng, W.Z. Weng, C.J. Huang, H.L. Wan, Carbon nanotube-supported Fe-Mn nanoparticles: a model catalyst for direct conversion of syngas to lower olefins, Catal. Today 215 (2013) 86-94.

[6] X. Song, W. Zhu, Y. Yan, H. Gao, W. Gao, W. Zhang, M. Jia, Selective oxidation of olefins with aqueous hydrogen peroxide over phosphomolybdic acid functionalized knitting aryl network polymer, J. Mol. Catal. A-Chem. 413 (2016) 32-39.

[7] F. Blanco-Bonilla, S. Lopez-Pedrajas, D. Luna, J.M. Marinas, F.M. Bautista, Vanadium oxides supported on amorphous aluminum phosphate: structural and chemical characterization and catalytic performance in the 2-propanol reaction, J. Mol. Catal. A-Chem. 416 (2016) 105-116.

[8] D. Do Van, T. Hosokawa, M. Saito, Y. Horiuchi, M. Matsuoka, A heterogeneous mesoporous silica-supported cyclopentadienyl ruthenium(II) complex catalyst for selective hydrosilylation of 1-hexyne at room temperature, Appl. Catal. A-Gen. 503 (2015) 203-208.

[9] J. Silvestre-Alberó, M.E. Domine, J.L. Jordá, M.T. Navarro, F. Rey, F. RodríguezReinoso, A. Corma, Spectroscopic, calorimetric, and catalytic evidences of hydrophobicity on Ti-MCM-41 silylated materials for olefin epoxidations, Appl. Catal. A-Gen. 507 (2015) 14-25.

[10] E.A. Quadrelli, J.-M. Basset, On silsesquioxanes' accuracy as molecular models for silica-grafted complexes in heterogeneous catalysis, Coord. Chem. Rev. 254 (2010) 707-728.

[11] Y. Pérez, D.P. Quintanilla, M. Fajardo, I. Sierra, I. del Hierro, Immobilization of titanium chiral alkoxides on SBA-15 and modelling the active sites of heterogeneous catalyst using titanium silsesquioxane complexes, J. Mol. Catal. AChem. 271 (2007) 227-237.

[12] C. Di Iulio, M.D. Jones, M.F. Mahon, Synthesis of Al(III) silsesquioxane complexes and their exploitation for the ring opening polymerisation of rac-lactide, J. Organomet. Chem. 718 (2012) 96-100.

[13] V. Ervithayasuporn, K. Kwanplod, J. Boonmak, S. Youngme, P. Sangtrirutnugul, Homogeneous and heterogeneous catalysts of organopalladium functionalized-polyhedral oligomeric silsesquioxanes for Suzuki-Miyaura reaction, J. Catal. 332 (2015) 62-69.

[14] V. Ervithayasuporn, S. Chimjarn, Synthesis and isolation of methacrylate- and acrylate-functionalized polyhedral oligomeric silsesquioxanes (T8, T10, and T12) and characterization of the relationship between their chemical structures and physical properties, Inorg. Chem. 52 (2013) 13108-13112.

[15] P.K. Baker, M.B. Hursthouse, A.I. Karaulov, A.J. Lavery, K.M.A. Malik, D.J. Muldoona, A. Shawcross, Seven-co-ordinate dibromo complexes of molybdenum(II) and tungsten(II) derived from $\left[\mathrm{MBr}_{2}(\mathrm{CO})_{3}(\mathrm{NCMe})_{2}\right]$. Crystal structures of the lsostructural complexes $\left[\mathrm{WX}_{2}(\mathrm{CO})_{3}(\mathrm{NCMe})\left(\mathrm{SbPh}_{3}\right)\right] \cdot \mathrm{CH}_{2} \mathrm{Cl}_{2}$ (X $=$ Br or I), J. Chem. Soc. Dalton Trans. (1994) 3493-3498.

[16] J. Gimenez, C.D. Nunes, P.D. Vaz, A.A. Valente, P. Ferreira, M.J. Calhorda, Heptacoordinate halocarbonyl molybdenum(II) and tungsten(II) complexes as heterogeneous polymerization catalysts, J. Mol. Catal. A-Chem. 256 (2006) 90-98.

[17] E.G. Vieira, I.V. Soares, N.C. da Silva, S.D. Perujo, D.R. do Carmo, N.L. Dias Filho, Synthesis and characterization of 3-[(thiourea)-propyl]-functionalized silica gel and its application in adsorption and catalysis, New J. Chem. 37 (2013) 1933-1943.

[18] N.L. Dias Filho, F.C.M. Portugal, J.M.F. Nogueira, P. Brandão, V. Félix, P.D. Vaz, C.D. Nunes, L.F. Veiros, M.J.V. de Brito, M.J. Calhorda, An oligosilsesquioxane cage functionalized with molybdenum (II) organometallic fragments, Organometallics 31 (2012) 4495-4503.
[19] P.K. Baker, The organometallic chemistry of halocarbonyl complexes of molybdenum (II) and tungsten (II), Adv. Organomet. Chem. 40 (1996) 45-115.

[20] R.M. Silverstein, G.C. Bassler, T.C. Morrill, Identificação por espectrometria de compostos orgânicos, Rio de Janeiro, third ed., 1979.

[21] M.V. Dias, M.S. Saraiva, P. Ferreira, M.J. Calhorda, Catalytic activity of molybdenum(II) complexes in homogeneous and heterogeneous conditions, Organometallics 34 (2015) 1465-1478.

[22] P.D. Ckiss, F. Rataboul, Fully condensed polyhedral oligosilsesquioxanes (POSS) from synthesis to application, in: Advances in Organometallic Chemistry, vol. 57, Elsevier Inc. Academic, The Netherlands, 2008, pp. 1-116.

[23] D.B. Cordes, P.D. Lickiss, F. Rataboul, Recent developments in the chemistry of cubic polyhedral oligosilsesquioxanes, Chem. Rev. 110 (2010) 2081-2173.

[24] E.J.R. Sudholter, R. Huis, G.R. Hays, N.C.M. Alma, Solid-state silicon-29 and carbon-13 NMR spectroscopy using cross-polarization and magic-anglespinning techniques to characterize 3-chloropropyl and 3-aminopropylmodified silica gels, J. Colloid Interf. Sci. 103 (1985) 554-560.

[25] E. Bayer, B. Pfleiderer, K. Albert, Investigations by ${ }^{29}$ Si cross-polarization magic angle spinning NMR spectroscopy of reaction pathways of silica gel polyfunctional modification, J. Chromatogr. 506 (1990) 343-355.

[26] P. Yin, Y. Tian, Z. Wang, R. Qu, X. Liu, Q. Xu, Q. Tang, Synthesis of functionalized silica gel with poly(diethylenetriamine bis(methylene phosphonic acid)) and its adsorption properties of transition metal ions, Mater. Chem. Phys. 129 (2011) 168-175.

[27] A. Arkhireeva, J.N. Hay, Synthesis of sub-200 mn silsesquioxane particles using a modified Stober sol-gel route, J. Mater. Chem. 12 (2003) 3122-3127.

[28] I.D. Mall, V.C. Srivastava, N.K. Agarwal, Removal of Orange-G and Methyl Violet dyes by adsorption onto bagasse fly ashd: kinetic study and equilibrium isotherm analyses, Dyes Pigments 69 (2006) 210-223.

[29] X.F. Sun, S.G. Wang, X.W. Liu, W.X. Gong, N. Bao, B.Y. Gao, H.Y. Zhang, Biosorption of Malachite Green from aqueous solutions onto aerobic granules: kinetic and equilibrium studies, Bioresour. Technol. 99 (2008) 3475-3483.

[30] I. Langmuir, The adsorption of gases on plane surfaces of glass, mica and platinum, J. Am. Chem. Soc. 40 (1918) 1361-1403.

[31] H.M.F. Freundlich, Uber die adsorption in Losungen, Z. Phys. Chem. 57 (1906) $358-385$.

[32] N.L. Dias Filho, F. Marangoni, R.M. Costa, Preparation, characterization, and $\mathrm{CuX}_{2}$ and $\mathrm{CoX}_{2}\left(\mathrm{X}=\mathrm{Cl}^{-}, \mathrm{Br}^{-}, \mathrm{ClO}^{-4}\right)$ adsorption behavior of a polyhedral oligomer silsesquioxane functionalized with an organic base, J. Colloid Interf. Sci. 313 (2007) 34-40.

[33] M.J. Temkin, V. Pyzhev, Recent modifications to Langmuir isotherms, Acta Physiochim. 12 (1940) 217-222.

[34] M.M. Dubinin, E.D. Zaverina, L.V. Radushkevich, Sorption and structure of active carbons I. Adsorption of organic vapors, Zh. Fiz. Khim. 21 (1947) $1351-1362$

[35] R. Qu, C. Sun, F. Ma, Z. Cui, Y. Zhang, X. Sun, C. Ji, C. Wang, P. Yin, Adsorption kinetics and equilibrium of copper from ethanol fuel on silica-gel functionalized with amino-terminated dendrimer-like polyamidoamine polymers, Fuel 92 (2012) 204-210.

[36] Y.S. Ho, G. McKay, Application of kinetic models to the sorption of copper (II) on to peat, Adsorpt. Sci. Technol. 20 (2002) 795-817.

[37] M.J.D. Low, Kinetics of chemisorption of gases on solids, Chem. Rev. 60 (1960) 267-307.

[38] F. Semnani, Z. Asadi, M. Samadfam, H. Sepehrian, Uranium(VI) sorption behavior onto amberlite CG-400 anion exchange resin: effects of $\mathrm{pH}$, contact time, temperature and presence of phosphate, Ann. Nucl. Energy 48 (2012) $21-24$.

[39] H. Martínez, M.F. Cáceres, F. Martínez, E.A. Páez-Mozo, S. Valange, N.J. Castellanos, D. Molina, J. Barrault, H. Arzoumanian, Photo-epoxidation of cyclohexene, cyclooctene and 1-octene with molecular oxygen catalyzed by dichloro dioxo-(4,4'-dicarboxylato-2,2'-bipyridine) molybdenum ${ }^{(\mathrm{VI})}$ grafted on mesoporous $\mathrm{TiO}_{2}$, J. Mol. Catal. A-Chem. 423 (2016) 248-255.

[40] Y. Leng, J. Liu, C. Zhang, P. Jiang, A polyhedral oligomeric silsesquioxane (POSS)-bridged oxo-molybdenum Schiff base complex with enhanced heterogeneous catalytic activity in epoxidation, Catal. Sci. Technol. 4 (2014) 997-1004.

[41] Y. Leng, J. Zhao, P. Jiang, J. Wang, Amphiphilic porous polyhedral oligomeric silsesquioxanes (POSS) incorporated polyoxometalate-paired polymeric hybrids: interfacial catalysts for epoxidation reactions, RSC Adv. 5 (2015) 17709-17715.

[42] M. Mirzaee, B. Bahramian, M. Mirebrahimi, Amine-functionalized boehmite nanoparticle-supported molybdenum and vanadium complexes: efficient catalysts for epoxidation of alkenes, Chin. J. Catal. 37 (2016) 1263-1274.

[43] M. Ghorbanloo, R. Bikas, G. Małecki, New molybdenum(VI) complexes with thiazole-hydrazone ligand: preparation, structural characterization, and catalytic applications in olefin epoxidation, Inorg. Chim. Acta 445 (2016) 8-16. 